\title{
Epigrafía y liturgia estacional entre el locutorio y el pasaje a la enfermería de la abadía de Santa María la Real de las Huelgas, en Burgos
}

Eduardo Carrero Santamaría Universitat Autònoma de Barcelona 
Resumen: El monasterio de Las Huelgas de Burgos conserva un conjunto de epígrafes en los dos pasos de comunicación entre el claustro de San Fernando y la zona de Claustrillas. Recogen fragmentos litúrgicos de los Salmos y de la Salve y el Oficio de completas que, por una parte, ponen de manifiesto el uso de ambos pasos como estaciones en la liturgia procesional de las monjas y, por

Aвstract: Cistercian monasteries figure in the popular imagination as embodiments of an austerely pure monastic spirituality. In turn, the interpretation of the physical remains of these monasteries focuses on the foundational moment, often identifying one of the small chapels located around the periphery of the monastic enclosure as the oratory founded by the original community, used until construction of the church reached a sufficiently advanced stage. In some cases, these popular traditions have a basis in reality, as we see in the case of the chapel of Santa Mariaa-Velha in Alcobaça (Portugal). This chapel, located some hundred metres from the monastery, temporarily served as the monastic church during the construction of the new abbey church, as a series of medieval inscriptions at the site tell us. In other cases, these chapels, usually located in the eastern portion of the monastic complex, pertained to the original layout of the monastery, serving such functions as the infirmary or abbot's chapel. These cult spaces formed part of the larger liturgical setting of the monastic otra, son un argumento más para interpretar el conjunto tardorrománico de las Claustrillas como la enfermería y el palacio abacial, siguiendo la topografía habitual de los monasterios cistercienses.

Palabras clave: Huelgas. Burgos. Císter. Epigrafía. Liturgia. Enfermería. Palacio abacial.

complex, being the site of occasional masses. Monastic infirmaries were generally located to the east of the main cloister, near the abbot's palace (where such a structure existed), which suggests that these chapels were shared between these two entities. The monastery of Las Huelgas in Burgos conserves a collection of inscriptions located in the corridors that communicated between the cloister of San Fernando and the area known as Las Claustrillas. These inscriptions include liturgical fragments of the Psalms, the Salve Regina, and the Office of Compline. On the one hand, these inscriptions underscore the liturgical use of these transitional spaces in the nuns' processions. On the other hand, they constitute another argument in favour of interpreting the late Romanesque complex of Las Claustrillas as an infirmary and abbot's palace, as we see in other Cistercian monasteries.

Keywords: Huelgas. Burgos. Cistercians. Epigraphy. Liturgy. Infirmary. Abbesses Palace. 
M uchos de los monasterios cistercienses gozan de tradiciones vernáculas, según las cuales alguna de las capillas situadas en su perímetro es interpretada como los restos de la fundación original. Un oratorio provisional en la que la comunidad se estableció y ofició, hasta que las obras de la iglesia hubieran avanzado lo suficiente para definir un espacio en el que celebrar, a la par que se finalizaban las dependencias del pabellón de monjes ${ }^{1}$. En algunos casos, la tradición tiene visos de realidad. La capilla de Santa Maria-a-Velha en Alcobaça, sita a un centenar de metros del monasterio, tuvo una funcionalidad temporal como iglesia monástica que nos dejó la serie epigráfica referente al traslado de la comunidad hasta la nueva y definitiva abadía, con el progreso en su construcción ${ }^{2}$. En otras ocasiones, estas capillas localizadas al Este del conjunto pertenecieron al proyecto original del monasterio, dedicándose a oratorios de la enfermería y del abad, generalmente parejos en uso. Se trató de espacios cultuales y, por lo tanto, objeto de un ceremonial notorio por parte de la comunidad que en determinadas ocasiones del año litúrgico se desplazaba en procesión hasta los mismos, donde al llegar se oficiaba

\footnotetext{
${ }^{1}$ Una reflexión al respecto en GARCÍA FLORES, A., Arquitectura de la orden del Císter en la provincia de Valladolid (II47-I5SIS), Valladolid: Junta de Castilla y León, 20II, pp. 87-I42.

2 BARROCA, M. J., Epigrafía medieval portuguesa (862-I422). Corpus epigráfico medieval portugués, 3 vols., Oporto, 2000, II-I: 245-248, 4I7-4I9 y 7 III-7I7.
}

o se realizaban una serie de cantos incluidos dentro de su liturgia particular. No en vano, en el monacato de tradición benedictina, las enfermerías se localizaron al Este del claustro principal, generalmente en las inmediaciones del palacio abacial -cuando éste existió-, lo que en muchas ocasiones significó que el oratorio fuera compartido por ambas instituciones ${ }^{3}$.

El funcionamiento autónomo de las capillas de la enfermería ya aparece legislado en los estatutos de la Orden cisterciense de II9I, cuando se autorizaba la celebración de la misa en la propia enfermería al abad de un desconocido monasterio dedicado a la Santa Cruz: Abbati de Sancta Cruce conceditur ut propter honestatem et Religiones piam suam in Infirmitorio Missam celebret ${ }^{4}$. Esta licencia presupone una inicial prohibición, pero también indica la importancia que adquirió la liturgia en dicho espacio y la necesidad de mantener en el mismo un lugar de culto al modo de los que ya existían en los monasterios benedictinos. Así, sólo tres años después, los estatutos generales de la orden establecieron la obligatoriedad de celebrar el oficio votivo de la Virgen en la enfermería, por

\footnotetext{
${ }^{3}$ Cf. BELL, D. N., "The Siting and Size of Cistercian Infirmaries in England and Wales", Studies in Cistercian Art and Architecture, 5 (1998), pp. 2II-238; CASSIDY-WELCH, M., Monastic Spaces and their Meanings: Thirteenth-Century English Cistercian Monasteries, Turnhout, 200I, pp. I4I-I42, y HALL, J., "East of the Cloister: Infirmaries, Abbots' Lodgings and other Chambers" en Perspectives for an Architecture of Solitude. Essays on Cistercians, Art and Architecture in Honour of Peter Fergusson, ed. Terry Kinder, Turnhout, 2004, pp. 199-2II.

${ }^{4}$ Publ. WADDELL, C., Twelfth-Century Statutes from the Cistercian General Chapter, Brecht, 2002, p. 227.
} 


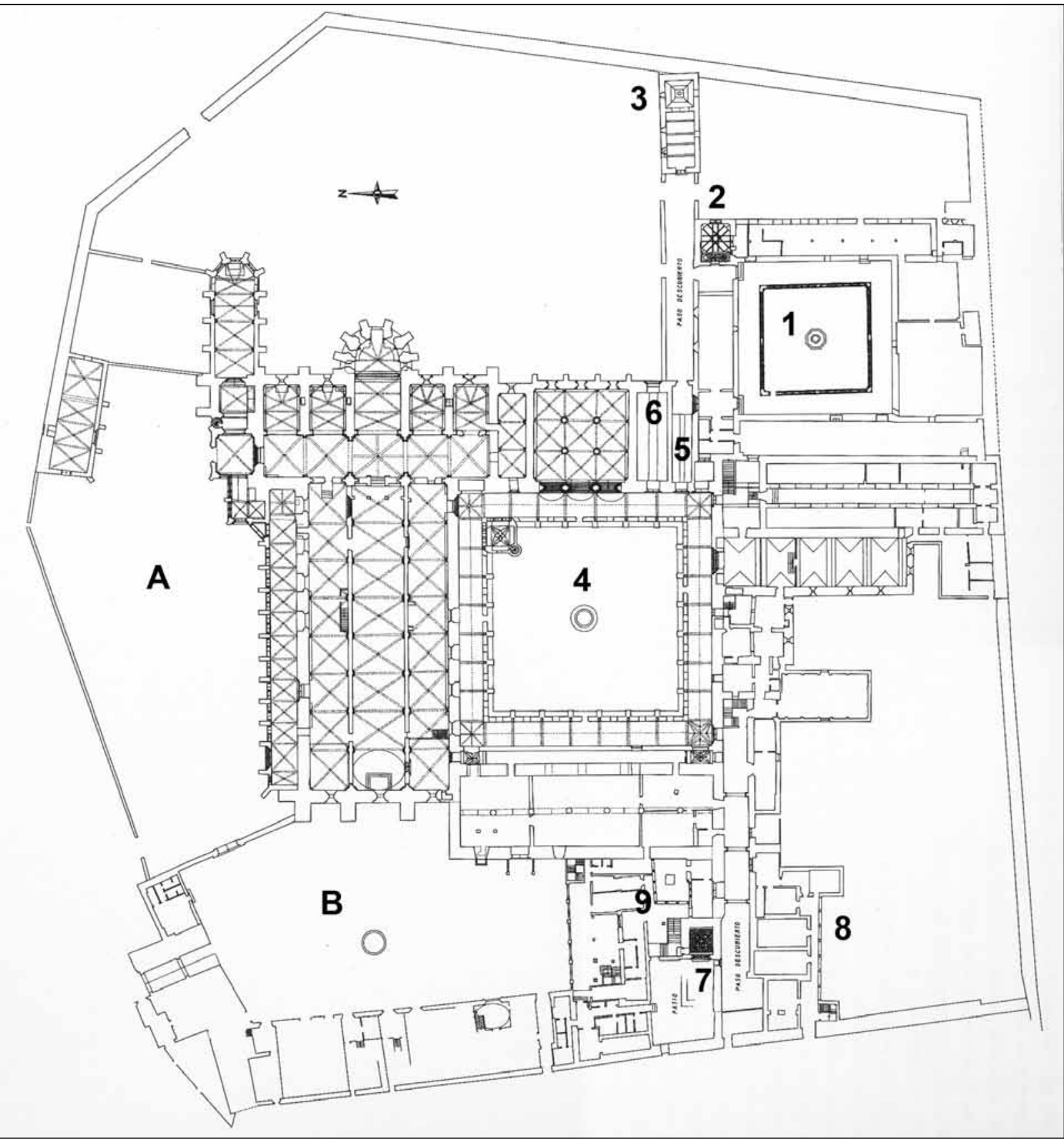

Fig. I - Santa María la Real de Las Huelgas (Burgos). Planta general (Corpus de Arquitectura Monástica Medieval, UAM). A y B. Compases. I. Claustrillas. 2. Capilla de la Asunción. 3. Capilla de Santiago. 4. Claustro de San Fernando. 5. Paso a Claustrillas. 6. Locutorio. 7. Capilla del Salvador. 8. Palacio abacial moderno. 9. Patio de Infantas. 
parte de monjes enfermos y enfermeros. Según destacó Manrique y recoge Waddell, esta costumbre fue otro de los préstamos litúrgicos tomados de los estatutos cluniacenses de Pedro el Venerable, donde también se rezaba el oficio de la Virgen en la enfermería 5 . Hubo enfermos que asistían a los oficios en el espacio coral, como bien nos revela que el trascoro entre la sillería de los monjes y el espacio reservado a los conversos en la nave de la iglesia sirviera precisamente para acoger a los menos graves, pero que no debían compartir el espacio coral con el resto de la comunidad ${ }^{6}$. Por su parte, los más delicados para moverse de la enfermería estaban obligados a rezar laudes y vísperas del oficio de difuntos, ritual que se complicaba durante la celebración de entierros de hermanos, si atendemos a los estatutos de II85 y iI867. Lo que se deduce de la documentación es la duplicidad de ámbitos litúrgicos entre enfermería y monasterio y cómo la primera funcionaba a pleno rendimiento, entendiéndose como un espacio litúrgicamente autónomo en el que los monjes se veían obligados a residir eventualmente.

\section{LA ENFERMERÍA Y EL PALACIO ABACIAL DE LAS HUELGAS, LA LÓGICA TOPOGRÁFICA DE LA TRADICIÓN BENEDICTINA}

La zona más antigua del monasterio burgalés de Santa María la Real de las Huelgas está constituida por las llamadas Claustrillas. Éstas son un patio porticado datado a finales del siglo XII, pero con un estudio estilístico y funcional complicado (fig. I). Parte de sus capiteles y arcos fueron repuestos en los años cincuenta y sesenta del siglo XX, sus muros perimetrales no muestran ninguna apertura de vanos asimilable a un monasterio inicial -con el consabido ritmo armarium, sala capitular, subida al dormitorio, locutorio, paso a

\footnotetext{
${ }^{5}$ MANRIQUE, A., Annales Cistercienses, 4 vols. Lyon, I642-I659, III, p. 285, y WADDELL, Twelfth-Century Statutes, op. cit., p. 28I.

${ }^{6}$ CARRERO SANTAMARÍA, E., "Una simplicidad arquitectónica por encima de los estilos. La iglesia del monasterio cisterciense entre espacios y funciones", en Mosteiros Cistercienses. História, Arte, Espiritualidade e Património, ed. J. Alburquerque Carreiras, 3 vols., Alcobaça, 2013, II, pp. II7-I38.

${ }^{7}$ WADDELL, Twelfth-Century Statutes, op. cit., pp. I25-I26 y I36-I38.
}

la enfermería y sala de monjes- y, por último, las excavaciones arqueológicas realizadas en el vergel en 2004 revelaron que se trata de una superficie profundamente alterada en época contemporánea. Mientras las dependencias a las que pudo dar acceso fueron transformadas en tiempos recientes, careciendo de alguna estructura histórica original, en el ángulo noreste del patio se abre la capilla de la Asunción, único vestigio medieval del entorno. Así las cosas, las Claustrillas han pasado por ser consideradas restos de la fundación monástica original que se vería ampliada en el siglo XIII con la gran iglesia gótica o, por el contrario, entre sus muros se ha querido ver una vieja residencia real perteneciente a los fundadores Alfonso VIII y Leonor de Inglaterra, a la par que la vecina capilla de la Asunción se ha interpretado como su capilla funeraria o, incluso, capilla del palacio real. Esta hipótesis sobre posibles construcciones regias se basaba en la interpretación más tradicional de la institución monástica. Si su iglesia iba a albergar los sepulcros de sus fundadores y de varios miembros de la casa real castellana, la propuesta palatina sobre todo encontraba apoyo en la teoría sobre palacios y residencias nobiliarias en monasterios desarrollada por Fernando Chueca Goitia ${ }^{8}$. Por el contrario, esta hipótesis sobre 'palacio monástico' real o nobiliario debiera ser reconsiderada. De hecho, en la mayor parte de las ocasiones no fue más allá de unos cuartos polifuncionales -muy lejos de la idea más romántica del palacio medieval-, y en la mayoría de las ocasiones situados entre las viviendas de los patios y compases de entrada y que servían de forma puntual y ocasional para acoger a monarcas, fundadores y protectores en las visitas esporádicas de una corte viajera?.

8 CHUECA GOITIA, F., Casas reales en monasterios y conventos españoles, Madrid, 1983. La propuesta del palacio en Las Huelgas a partir del testimonio documental del Tudense y de otro diploma datado en I292, TORRES BALBÁS, L., "Las yeserías descubiertas recientemente en Las Huelgas de Burgos. Contribución al estudio de la decoración arquitectónica hispanomusulmana", Al-Ándalus, VIII-I4 (1943), reed. en Obra dispersa I. AlÁndalus. Crónica de la España musulmana, vol. 2, Madrid, I98I, pp. I84-237, y PÉREZ HIGUERA, M. T., "El primer mudéjar castellano: casas y palacios", en Casas y palacios de Al-Ándalus. Siglos XII y XIII, ed. J. Navarro Palazón, Barcelona, I995, pp. 303-3I4, en particular, 3II.

9 CARRERO SANTAMARÍA, E., "Monjas y conventos en el siglo XIV", en El Libro de Buen Amor: texto y contextos, eds. Guillermo Serés, Daniel Rico y Omar Sanz, Valladolid, 2008, pp. 207-235. 


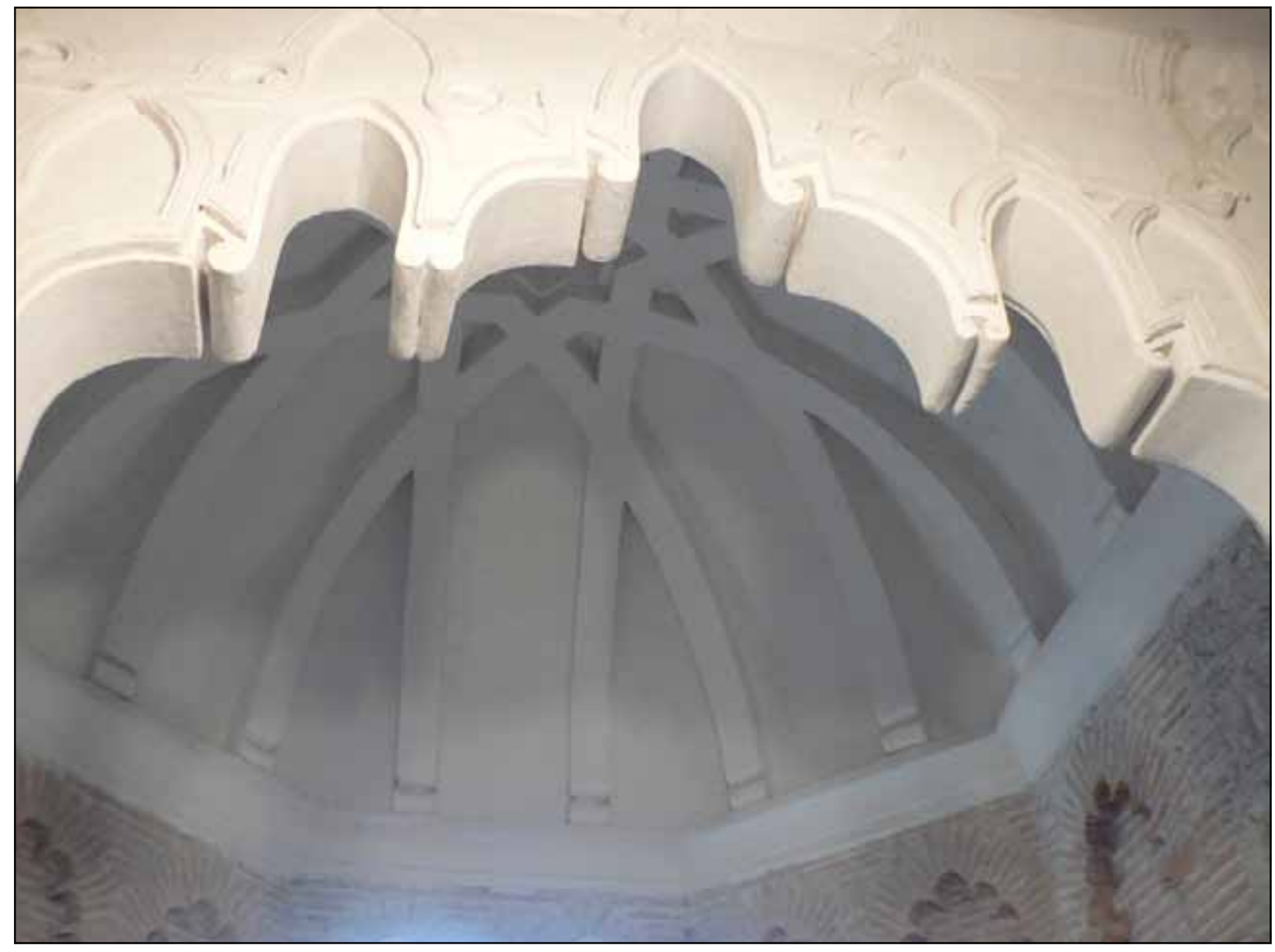

Fig. 2 - Santa María la Real de Las Huelgas. Capilla de la Asunción. Arco de entrada y bóveda.

En Las Huelgas, si las Claustrillas hubieran sido estructuras procedentes de un entorno palaciego real, la relación topográfica entre la capilla de la Asunción y el patio habría sido muy distinta, según se deduce de su comparación con los palacios islámicos con su qubba correspondiente. Como demuestran los ejemplos musulmanes contemporáneos que propone Juan Carlos Ruiz, la capilla se habría localizado en el centro de una de las galerías claustrales y no desplazada a uno de sus rincones, como se construyó realmente ${ }^{10}$.

${ }^{10}$ RUIZ SOUZA, J. C., "La planta centralizada en la Castilla bajomedieval: entre la tradición martirial y la qubba islámica; un nuevo capítulo de particularismo hispano", Anuario del Departamento de Historia y Teoría del Arte (UAM), I3 (200I), pp. 9-36.
Como se ha insistido en diversas ocasiones ${ }^{11}$, la funcionalidad inicial y transitoria de la Asunción pudo haber sido la de iglesia temporal del monasterio, adyacente al núcleo de las Claustrillas. Durante la fundación inicial albergó los sepulcros de la familia regia, entre cuyos restos quizás estuvo el célebre y reconstruido arcosolio con una Assumptio animae, hoy conservado en el muro sur de la capilla. Esto debió ser antes de su transformación en el espacio que hoy podemos ver (fig. 2), mediante las

${ }^{11}$ LÓPEZ DE GUEREÑO, M. T., "Capilla de la Asunción. Santa María la Real de las Huelgas (Burgos)”. Monjes y monasterios. El Cister en el medievo de Castilla y León, coord I. G. Bango Torviso, Valladolid, I998, pp. 282-283, y RUIZ SOUZA, "La planta centralizada”, op. cit., recogiendo la bibliografía precedente. 


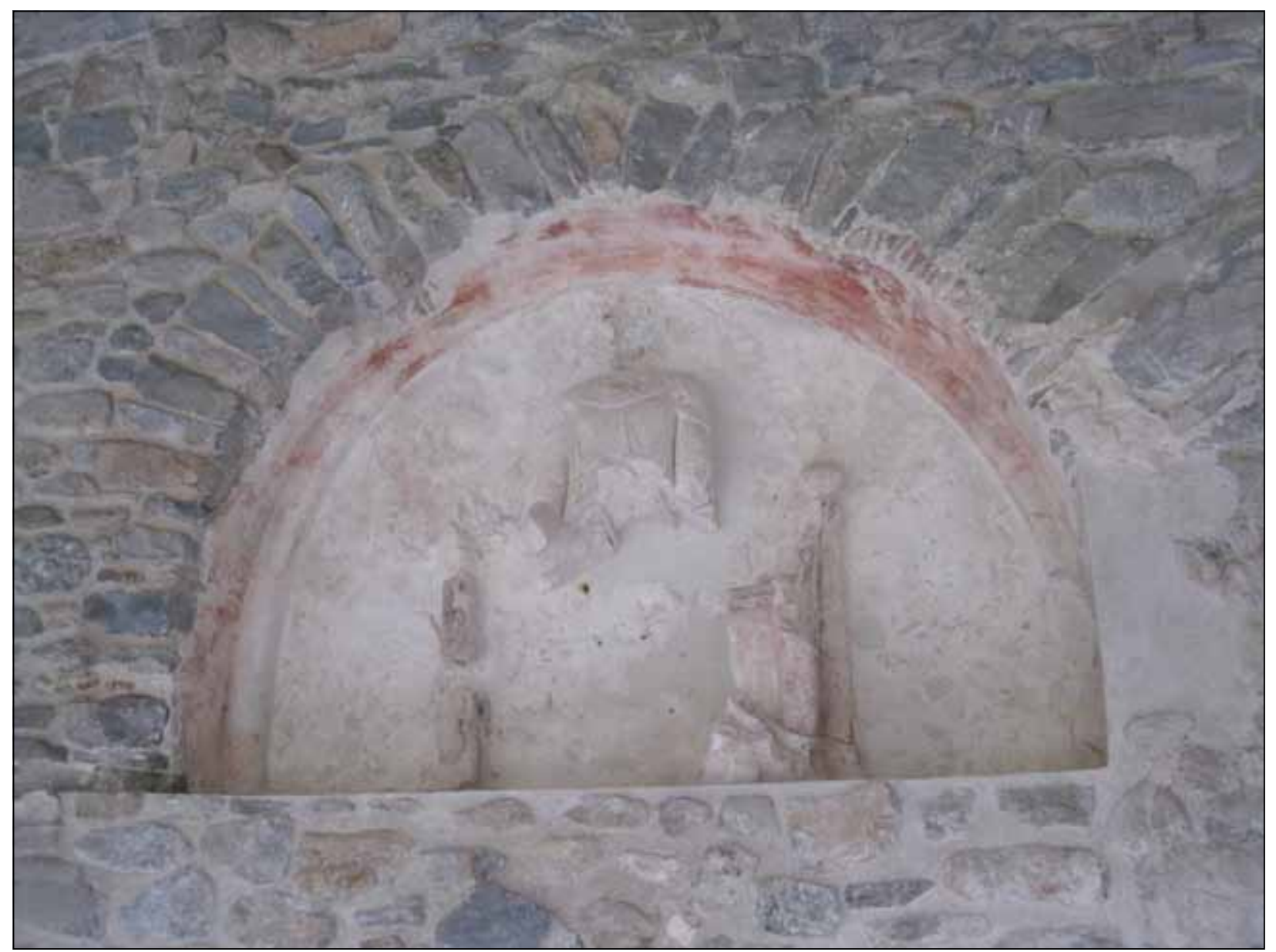

Fig. 3 - Santa María de Ripoll (Gerona). Virgen del claustro.

yeserías que cubren sus muros y que se datan entre la primera mitad y el tercer cuarto del siglo XIII ${ }^{12}$. El uso originario de este espacio, también debiera ser revisado y no en función de los condicionamientos regios que han marcado toda la historiografía dedicada al monasterio burgalés. Uno de los problemas que siempre ha acarreado la construcción e interpretación espacial de Las Huelgas es que se ha realizado subordinada al legendario de su fundación. De este modo, si las décadas más tempranas de su historia son especialmente oscuras, no tenemos elementos de juicio sólidos para plantear el calibre de la

12 TORRES BALBÁS, "Las yeserías", op. cit., p. 225, y RUIZ SOUZA, "La planta centralizada", op. cit., p. I6. intervención real en el desarrollo constructivo del monasterio hasta época de Alfonso X, bajo cuyo reinado se finalizó la obra de la iglesia y se organizó su çemeterio, con el traslado y definitivo acondicionamiento de los sepulcros reales en su interior ${ }^{13}$.

13 Veánse aquí SÁNCHEZ AMEIJEIRAS, R., "El 'çemeterio real' de Alfonso VIII en Las Huelgas de Burgos", Semata, Io (I998), pp. 77-I09, e Id., "La memoria de un rey victorioso. Los sepulcros de Alfonso VIII y la fiesta del triunfo de la Santa Cruz", en Grabkunst und Sepulkralkultur in Spanien und Portugal, eds. B. Borngässer, H. Karge y B. Klein, Frankfurt, 2006, pp. 289-315; PALOMO, G. y RUIZ SOUZA, J. C. "Nuevas hipótesis sobre Las Huelgas de Burgos: Escenografía funeraria de Alfonso X para un proyecto inacabado de Alfonso VIII y Leonor Plantagenêt", Goya, 316-317 (2007), pp. 2I-44; ALONSO ÁLVAREZ, R., "La cabecera de las iglesias cistercienses femeninas en la Corona de Castilla: Clausura, cura monialum y representación aristocrática y regia”, Hortus Artium Medievalium, I5-2 (2009), 
Antes de lanzarnos a interpretaciones simbólicas a partir de la personalidad de los fundadores o de buscar implicaciones de la política contemporánea en la construcción o decoración de la fábrica monástica, no estaría mal comenzar situando el monasterio en un contexto cisterciense. Con esto quiero decir que no debemos partir de un bluf metodológico en el que la historia de la fundación y la fascinante personalidad de los monarcas fundadores -bañadas ambas, de nuevo, en romanticismo decimonónico- terminen funcionando como pie forzado para nuestro análisis de un proceso constructivo y, sobre todo, de una interpretación funcional. Además, en pos de la distinción de la monarquía y del papel regio en la construcción, se ha olvidado que Las Huelgas funcionó como comunidad autónoma, carente incluso de supervisión episcopal, que sus abadesas fueron grandes damas de Castilla directamente dependientes de Roma y que, con seguridad también patrocinaron unas obras que no sólo contaron con los monarcas como promotores. Ésta es una vía de análisis que todavía nos aportará novedades en la historia del monasterio como revela, ya en época moderna, la remodelación de la fábrica durante el abadiato de dońa Ana de Austria y su clara participación en la misma ${ }^{14}$.

Creo que todos somos conscientes de que la arquitectura del Císter, desde la perspectiva del análisis del espacio y su función, es una historia de excepciones que confirman reglas. Como decía, la comparación de la articulación funcional de la topografía monástica

pp. 34I-53, e Id., "La memoria de Alfonso VIII de Castilla en las Huelgas de Burgos: Arquitectura y liturgia funeraria”, en I2I2, un año, un reinado, un tiempo de despegue. XXIII Semana de Estudios Medievales Nájera, del 30 de julio al 3 de agosto de 20I2, ed. Esther López Ojeda, Logroño, 2013, pp. 349-76.

${ }^{14}$ CARRERO SANTAMARÍA, E., "The creation and use of space in the Abbey of Santa María la Real de Las Huelgas, Burgos: architecture, liturgy, and paraliturgy in a female Cistercian monastery", Journal of Medieval Iberian Studies, 6-2 (20I4), pp. I-23. En paralelo, merece la misma reconsideración la figura de la Señora de las Huelgas y el patrocinio familiar de nobles y casa real en otros monasterios cistercienes, cf. ALONSO ÁLVAREZ, R., "Los promotores de la Orden del Císter en los reinos de Castilla y León: familias aristocráticas y damas nobles", Anuario de Estudios Medievales, 37-2 (2007), pp. 653-7IO; BAURY, G., Les religieuses de Castille. Patronage aristocratique et ordre cistercien XIIe-XIIIe siècles, Rennes, 20I2, e Id., "Les religieuses de Castille. Patronage aristocratique et ordre cistercien XIIe-XIIIe siècles", en Mosteiros cistercienses. História, Arte, Espiritualidade e Património, ed. J. Alburquerque Carreiras, 3 vols., Alcobaça, 2013, III, pp. 35-46. debe buscarse en su contexto contemporáneo y, así, comprobaremos que la supuesta anormalidad de las Claustrillas no es sino una regla común a todos los monasterios de la época. Al comenzar el artículo indicaba las historias fundacionales y su relación con capillas provisionales que finalmente devendrían en la zona ocupada por estructuras de servicios básicas dentro de la arquitectura de tradición benedictina como la enfermería y el palacio de la abadesas. En este sentido, las Claustrillas y la capilla de la Asunción adoptaron una posición canónica en ambos sentidos, el tratarse en un transitorio ámbito de culto para la primera comunidad de monjas y, después, convertirse en enfermería y, con seguridad, palacio abacial y no un desesperante rompecabezas de suposiciones en relación a la pareja de fundadores y su huella material. A tal efecto, tras el traslado de los sepulcros y la ocupación de la iglesia gótica llevaría a una ulterior remodelación de la capilla ya en pleno siglo XIII, con la decoración hispanomusulmana que podemos ver hoy. Del proceso tanto de ocupación inicial y traslado, como de su topografía como espacio sanitario y, como veremos a continuación, palatino tenemos un importante número de paralelos. Sin salir de la Península Ibérica, podríamos esgrimir los ejemplos de las abadías cistercienses de Santes Creus, Poblet, Iranzu, Valldigna, La Espina, etcétera $^{15}$. Algo más puede añadirse en este sentido. Los más críticos podrían cuestionarse por qué se realizó un claustro tan lujoso en tanto que las obras de la iglesia se retrasaban con un largo y complejo programa constructivo. Pues bien, es aquí donde tenemos que reivindicar la figura de la abadesa de Las Huelgas. Si sabemos que por regla general los palacios abaciales se situaron al Este del conjunto monástico y en la

${ }^{15}$ CARRERO SANTAMARÍA, E., "Arte y liturgia en los monasterios de la orden de Cister. La ordenación de un 'ambiente estructurado'." Actas. III Congreso Internacional sobre el Cister en Galicia y Portugal, 2 vols., Ourense, 2006, I, pp. 503-565, en particular, pp. 557-558, ID., "Monjas y conventos", op. cit., pp. 2II-2I2, e ID., "The creation of use of space", op. cit. Para el caso concreto de Santes Creus, cuya historia corre en buena medida paralela a la de Las Huelgas, ESPAÑOL, F., "Reial o abacial? El palau de Santes Creus revisat”, Estudis Històrics i Documents dels Arxius de Protocols, XIV (1996), pp. 167-I86. Sobre el contexto anglosajón, con alusiones al resto de Europa, BELL, "The Siting and Size", op. cit.; CASSIDY-WELCH, Monastic Spaces, op. cit., pp. I4I-I42, y HALL, "East of the Cloister", op. cit. 
vecindad de la enfermería con la que llegaron hasta a compartir capilla, creo que no hay ningún problema en vincular las Claustrillas y su lujosa arquitectura y escultura a la figura de la abadesa y su palacio, precisamente en unas fechas -el período charnela entre los siglos XII y XIII- en las que su poder como cabeza de la orden y su más o menos continua pertenencia a la aristocracia castellana se estaban asentando ${ }^{16}$. Mientras, el proyecto de la monumental nueva iglesia continuaba su camino en paralelo con las obras del resto del conjunto monástico, dependientes de los vaivenes económicos y voluntades particulares de los representantes de la corona castellana, al fin y al cabo patronos y responsables de un templo que nacía con la intención de convertirse en gran cementerio de un buen número de miembros de su linaje ${ }^{17}$. ¿Estaríamos aquí por tanto ante dos proyectos en paralelo promovidos desde dos instituciones diferentes? La iglesia y núcleo principal del monasterio dependió de la casa real y de ahí los paros y nuevos impulsos en su fábrica. Mientras, la construcción del entorno del palacio abacial y circunstancial alojamiento de la comunidad hasta la finalización de las obras del gran monasterio dependería económicamente de la voluntad de las propias monjas y de una abadesa que, por intención de los fundadores, había pasado a convertirse en la máxima dignataria de la rama femenina del Císter en Castilla. En este marco de residencia para abadesasinfantas y para abadesas aristócratas debe entenderse

16 Sobre el proceso de consolidación del poder abacial en el monasterio, BAURY, op. cit., pp. I38-I59. Revindicando este asunto para la comprensión del conjunto de las Claustrillas, CARRERO, "The creation and use of space", op. cit.

${ }_{17}$ El proceso constructivo de la iglesia y su cronología han suscitado un interesante debate: VALLE PÉREZ, J. C., "Significación de la iglesia en el panorama de la arquitectura de la Orden del Císter", Reales Sitios, ios (1990), pp. 49-56, KARGE, H., "Die königliche Zisterzienserinnenabtei Las Huelgas de Burgos und die Anfänge der gotischen Architecktur in Spanien", en Gotische Architektur in Spanien: Akten des Kolloquiums der Carl JustiVereinigung und des Kunstgeschichtlichen Seminars der Universität Göttingen, ed. Christian Freigang, Vervuert, I999, pp. 13-40, VALLE PÉREZ, J. C., "La construcción del monasterio de las Huelgas”, en Vestiduras ricas. El monasterio de Las Huelgas y su época (II70-1340), coord. J. Yarza Luaces, Madrid, 2005, pp. 35-50; PALOMO y RUIZ SOUZA, op. cit. Recogiendo las hipótesis de los anteriores, D’EMILIO, J., “The Royal Convent of Las Huelgas: Dynastic Politics, Religious Reform and Artistic Change in Medieval Castile." Studies in Cistercian Art and Architecture: Cistercian Nuns and Their World, ed. Meredith Parsons Lillich, 6 (2005), pp. I9I-282.

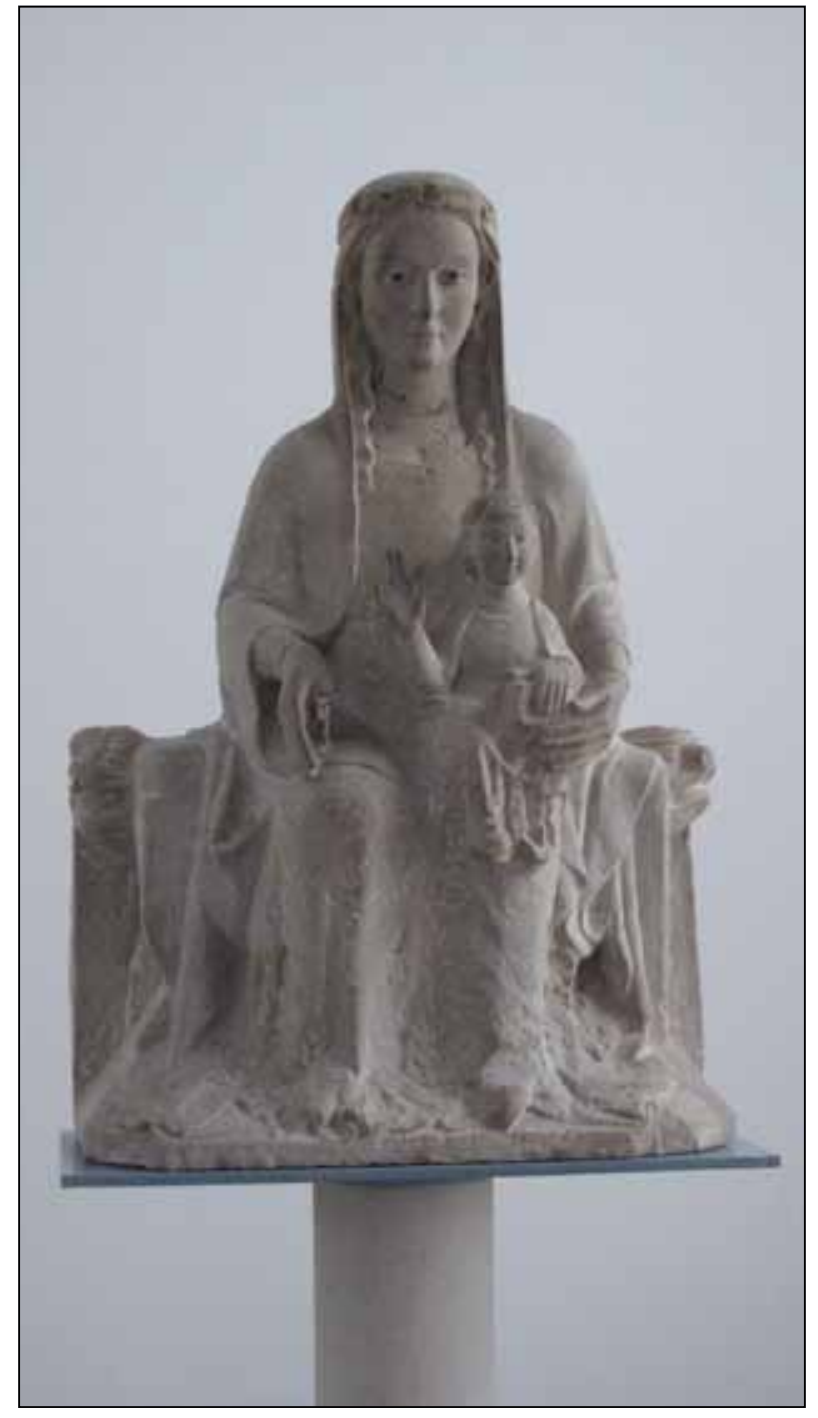

Fig. 4 - Santa María de Vallbona de les Monges (Lérida). Virgen del claustro.

una fábrica tan lujosa como es, al fin y al cabo, la escultura de las Claustrillas, con sus capiteles vegetales y clasicistas machones centrales en la órbita estilística de lo que hemos dado en llamar tardorrománico ${ }^{18}$.

${ }^{18}$ Sobre los mismos, HERNANDO GARRIDO, J. L., "Las claustrillas de Las Huelgas, San Andrés de Arroyo y Aguilar de Campo. Los repertorios ornamentales y su eclecticismo en la escultura del tardorrománico castellano", Anuario del Departamento de Historia y Teoría del Arte UAM, 4 (1992), pp. $53-74$. 


\section{LA ENFERMERÍA DE LAS HUELGAS Y LOS} ECCLESIASTICA OFFICIA CISTERCIENSES

Además de los análisis de topografía monástica comparada y del patronazgo abacial dentro de la obra del monasterio, un testimonio documental refrenda la hipótesis que reinterpreta las Claustrillas como patio de la enfermería y del palacio de la abadesa y a la Asunción como su capilla. En el archivo del monasterio se conserva un códice del siglo XIV, algunos de cuyos contenidos fueron recogidos por Higini Anglès. Éste lo consideró el libro de costumbres del monasterio, es decir, su directorio litúrgico ${ }^{19}$. Efectivamente, el manuscrito es la adaptación de los Ecclesiastica Officia cistercienses para la abadía burgalesa. Al contrario que otras órdenes como los benedictinos, en los que un libro de costumbres propio y particular para cada casa regía la vida litúrgica de la misma -ya fuera de redacción propia, ya estuviera copiado o inspirado por otro- el Císter optó por adoptar un códice litúrgico común, que reglamentara la vida de sus monasterios. A tal fin, se redactaron unos Ecclesiastica Officia que, a pesar de la voluntad de unificar criterios, fueron copiados con muchas particularidades. Tanto así, que cada monasterio realizó y utilizó un ejemplar propio en el que si, a nivel global, se respetaron el orden de los oficios, los cargos en la comunidad o el desarrollo del ańo litúrgico, a nivel puntual, las rúbricas dieron cuenta de las particularidades arquitectónicas de cada instituto, recogiendo algunas singularidades sobre capillas o disposición topográfica que permitían poner en escena la liturgia de la orden en cada institución. El códice en cuestión requiere de un estudio monográfico pero, a nuestro interés, recoge un dato básico para interpretar la zona Este del conjunto. Al referir las disposiciones a tomar por la enfermera a la muerte de una de las hermanas indican cómo, desde la enfermería, aquélla debía avisar a las restantes monjas tocando la tabla por

\footnotetext{
19 ANGLÈS, H., El Códex Musical de las Huelgas, 3 vols., Barcelona I93I. También J. C. ASENSIO PALACIOS, en El códice de las Huelgas, introducción, edición y transcripción musical e índices de J. C. Asensio Palacios, introducción, edición y traducción de los textos de J. Lorenzo Arribas, Madrid, 200I.
}

la claustra nueva ${ }^{20}$. Lógicamente, la interpretación pasa por la existencia de una claustra vieja, en la que se encontraría la enfermería y posiblemente el primer palacio abacial y que debe tratarse de las señaladas Claustrillas. Su cronología a caballo entre los siglos XII y XIII, parece convertir la fase inicial de la capilla y el vecino claustro en el núcleo inicial del conjunto, núcleo a todas luces transitorio mientras se construía la gran iglesia monástica, siguiendo la lógica espacial de la arquitectura del Císter. Así se mantenía el lugar por antonomasia para la localización de palacios abaciales y enfermerías monásticas. Allí debió permanecer el palacio hasta el siglo XVI, fecha en que buena parte de las residencias abaciales de los monasterios cistercienses peninsulares habían cambiado su ubicación hasta un punto más cercano a la portería del conjunto. Así, se levantó el nuevo palacio en el lado suroeste del conjunto, en tanto que antigua residencia abacial debió caer en desuso hasta desparecer. En fecha imprecisa también desapareció la enfermería, en tanto que la capilla común a ambos espacios fue el único elemento del conjunto que pervivió.

\section{CLAUSTROS, IMÁGENES, LITURGIA MARIANA Y CAPILLAS DE LA ENFERMERÍA}

Pero aún hay más. El desarrollo de la liturgia estacional por el entorno del monasterio y la interconexión entre sus espacios gracias a las procesiones vuelven a refrendar el uso y función de la capilla de la Asunción, permitiendo hacer un apunte de topografía litúrgica sobre los espacios que conectaban las zonas más importantes del monasterio. Es bien sabido que todas las instituciones eclesiásticas contaron con más de un punto donde desarrollar la liturgia. Catedrales y monasterios se proyectaron con complejas topografías - a veces improvisadasque permitían transitar de un lugar a otro en función del año litúrgico o del tipo de celebración a realizar, y representar la liturgia en escenarios diferentes. En los

\footnotetext{
${ }^{20}$ Quatro órdenes del áureo número e otros tractados e cerimonias que pertenesçen a la orden de Çistel, Archivo de Santa María la Real de Las Huelgas de Burgos, ms. 6, f. LXXIX v., CARRERO SANTAMARÍA, E., "Arte y liturgia”, op. cit., pp. 557-558 e ID., "Monjas y conventos", op. cit.
} 


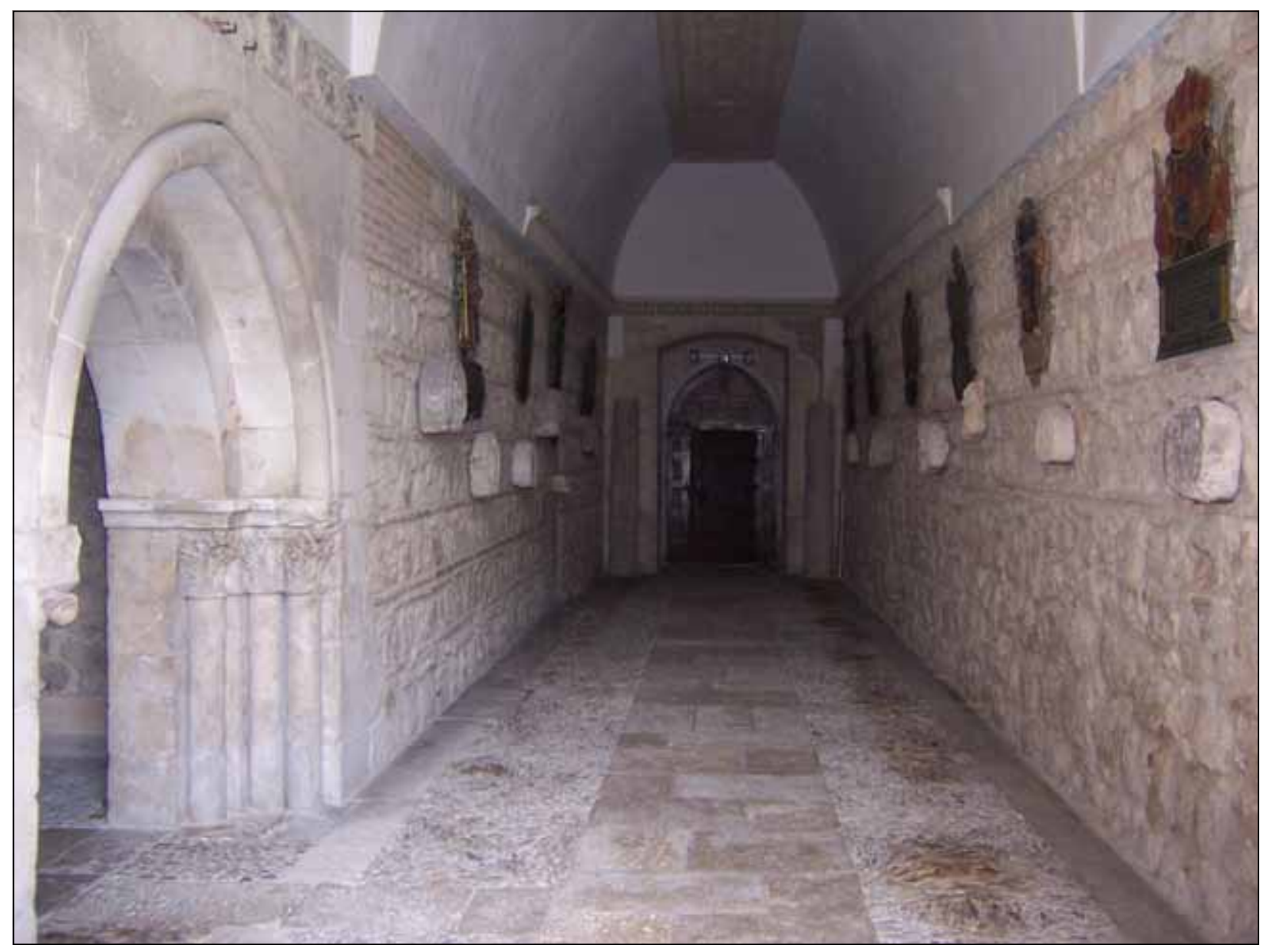

Fig. 5 - Santa María la Real de Las Huelgas. Paso a las Claustrillas, visto desde el Este.

monasterios, esta 'topografía compleja' pervivió mejor en las clausuras, descrita en ordinarios y otros libros litúrgicos. En este contexto, los cenobios benedictinos contemplaron la construcción en su entorno de una capilla generalmente dedicada a la Virgen, situada en las inmediaciones de la sala capitular y que realizaba las funciones de oratorio de la enfermería con claras connotaciones funerarias, además de ser el punto de llegada de algunos momentos de la liturgia estacional, según estipulaban puntualmente los libros de costumbres de cada institución ${ }^{21}$. Este uso, muy bien documentado

${ }^{21}$ HAGER, G., "Zur Geschichte der abendlandischen Klosteranlage. V. Die Marienkapelle.” Zeitschrift für christliche Kunst, I4 (I9OI), pp. 193-204, y REVEYRON, N., "Marcigny, Paray-le-Monial et la question de la chapelle en Cluny, afectó a todos los monasterios benedictinos, incluidos los prioratos catedralicios ingleses. Siguiendo una topografía sagrada casi estereotipada, la capilla, la enfermería y en ocasiones el palacio abacial se situaban en un conjunto de edificios a veces organizados en torno a un patio secundario, al este de las dependencias que ocupaban la galería oriental del claustro mayor. El uso fúnebre ha sido sobradamente vinculado a la cercanía de la capilla a la sala capitular, donde se realizaba la lectura del Liber capituli, de clara significación funeraria y que llegó a modificar la propia estructura del capítulo con la

mariale dans l'organisation spatiale des prieurés clunisiens au XIe-XIIe siècle”, Viator, 4I Multilingual (2010), pp. 63-94. 
fundación de altares en su interior e incluso su apertura mediante ábsides, en paralelo a la conversión de la sala en panteón de abades.

Tocante a la liturgia, desde el siglo XI contamos con noticias sobre la participación de esta iglesia menor en los oficios. Carolyn M. Malone ha destacado cómo la capilla de Santa María en Cluny funcionó como iglesia paralela durante el rezo de tercia en los oficios de Viernes Santo, en tanto que la iglesia mayor era preparada para la continuación del ceremonial del Triduo Sacro. También era punto focal de las procesiones los miércoles y viernes después de maitines o vísperas, y de otras ocasionales durante la Cuaresma, o entre la Trinidad y Todos los Santos ${ }^{22}$. Del mismo modo funcionaron las procesiones dominicales y las festivas de Navidad -claramente vinculadas con el ciclo mariano hasta la Asunción. En ésta última festividad, descrita en el Liber Tramitis del abad Odilon (994-I048), la comunidad procesionaba hasta la capilla de Santa María portando las imágenes de Cristo y la Virgen ${ }^{23}$.

Pero todavía faltaban unos años para que las capillas de la enfermería gozaran de un especial singularidad en el culto mariano. De hecho, hasta las medianías del siglo XII la advocación de la capilla a la Virgen era una regla general pero no absoluta, y buena parte de ellas podían tener dedicaciones diversas, como la de San Benito de la enfermería, en San Benigno de Dijon, o la de San Pedro, en Ainay. En los alrededores de II45 y en el monasterio de Cluny, el abad Pedro el Venerable finalizó su revisión de los estatutos en los cuales se prescribía el rezo de la Salve en la procesión de la Asunción y en las restantes procesiones anuales que ponían en comunicación la iglesia mayor del monasterio con la

\footnotetext{
${ }^{22}$ MALONE, C. M., "Interprétation des pratiques monastiques à SaintBénigne de Dijon d'après ses coutumiers d'inspiration clunisienne", en From Dead of Night to End of Day. The Medieval Customs of Cluny, eds. S. Boyton e I. Cochelin, Turnhout, 2005, pp. 22I-250, en particular, 228-230.

${ }^{23}$ FULTON BROWN, R., "Quae est ista quae ascendit sicut aurora consurgens?: The Song of Songs as the Historia for the Office of the Assumption", Mediaeval Studies, 60 (1998), pp. 55-I22. Aunque centrada en el papel del atrio de las iglesias, véase el panorama y las posibilidades de estudio en KRÜGER, K., "Monastic Customs and Liturgy in the Light and the Architectural Evicence: A Case Study on Processions (Eleventh-Twelfth Centuries)", en From Dead of Night to End of Day. The Medieval Customs of Cluny, eds. S. Boyton e I. Cochelin. Turnhout, 2005, pp. 19I-215.
}

capilla dedicada a la Virgen, que se situaba en la huerta monástica:

Statutum est ut antiphona de sacra mater
domini facta, cuius principium est 'Salve,
regina misericordia', in festo assumptionis
ipsius, dum processio fit, a convento cantetur.
Et insuper in processionibus, quae a principali
ecclesia Apostolorum ad eiusdem matris virginis
ecclesiam ex more funt, exceptis illis sanctorum
festivitatibus, in quibus mos antiquus exigit ad
eosdem sanctos pertientia decantari ${ }^{24}$.

En el Císter, en in74 se legisló el canto de la Salve en los laudes de todos los días de la infraoctava. En I2I8 el capítulo general la introdujo en el canto diario, después de capítulo y ante el altar, situación en la que variará de rezo comunitario a privado hasta su definitiva declaración como común en I239. En I228 se estableció todos los viernes después de capítulo y de los siete salmos penitenciales en la iglesia, y en I24I pasó a cantarse después de Prima en el coro, y de Prima a después de Completas en I25 ${ }^{25}$.

Como hemos tenido ocasión de ver líneas arriba, esta localización de la enfermería en los monasterios de San Benito se perpetuó en los monasterios cistercienses con un mismo uso, tanto que en ocasiones son la mejor fuente y el mejor paralelo para el estudio de las topografías benedictinas ${ }^{26}$. En el caso del uso procesional de la capilla de la enfermería con connotaciones marianas, según quedó estipulado para Cluny por Pedro

\footnotetext{
${ }^{24}$ CANAL, J. M., Salve Regina Misericordiae. Historia y leyendas en torno a esta antifona, Roma, 1963 , pp. 49-50.

25 Ibid., pp. II5-II7.

${ }^{26}$ La costumbre sería recogida por otras órdenes, como franciscanos y dominicos, según ha puntualizado Mercedes Pérez Vidal para los monasterios femeninos de la orden de Santo Domingo: PÉREZ VIDAL, M., "Observancia y rigorismo. Consecuencias de la reforma de la Orden de Predicadores y de algunos movimientos rigoristas en la liturgia y arquitectura de los monasterios de dominicas de la "Provincia de España»", en Literatura medieval y renacentista en España. Líneas y pautas, eds. N. Fernández Rodríguez y M. Fernández Ferreiro, Salamanca, 20I2, pp. 80I-8I2; ID., Arte y arquitectura de los monasterios de la Orden de Predicadores de la 'Provincia de España'. Desde los orígenes hasta la reforma (I2I8-I506), 2 vols., Tesis Doctoral, Universidad de Oviedo, 2012, I, pp. I78-I95, e ID., "La liturgia procesional de completas en el ámbito de los monasterios femeninos de la Orden de predicadores en Castilla." Hispania Sacra, en prensa.
} 
el Venerable, también fue heredado en el Císter. Sin ir más lejos, la colección de estatutos procedente del monasterio de Santa María de Bujedo (Burgos) describe el desarrollo del oficio mariano en el monasterio y la enfermería, situándolo entre los oficios canónicos y el de difuntos, según ya recogían los textos legislativos de la Orden:

\section{Statutum est in genereali capitulo ut} hore beate Marie dicantur in conuentu et in infirmitorio hoc modo... (...) Hore beate marie cantentur in infirmitorio omni tempore, exceptis sollempnitatibus, et octabis assumptionis eiusdem, et diem natalis domini et pasce et pentecostem ${ }^{27}$.

Lamentablemente, nada resta de esta zona en Bujedo. Por último y en consonancia con este renovado culto mariano en el monacato benedictino de mediado el siglo XII, precisamente en estas décadas comienzan a documentarse las imágenes claustrales dedicadas a la Virgen. Además de los consabidos capiteles figurados, todo claustro fue decorado con imágenes en sus muros perimetrales y en los machones angulares, que pudieron ser tanto esculpidas como pintadas. Las vírgenes de claustro formaron parte de estos programas iconográficos. Siendo el punto de llegada de las procesiones marianas generalizadas desde este siglo XII, dichas imágenes comenzaron a convertirse en una pieza de culto habitual que se extendió también a catedrales y otras órdenes ${ }^{28}$. Su progresiva importancia - pensemos en el crecimiento de procesiones a la Virgen con la consolidación de sus festividades más importantes: Natividad, Asunción, Anunciación, Inmaculada Concepción, misas marianas propias, etc.-, en ocasiones terminó generando capillas propias y dotaciones privadas por parte de abades o protectores de cada institución, sitas en los ángulos del perímetro claustral y en donde se realizaban las estaciones procesionales. Las capillas del claustro de San Fernando

${ }^{27}$ Publ. WADDELL, Twelfth-Century Statutes, op. cit., pp. 722 y 723.

${ }^{28}$ CARRERO SANTAMARÍA, E., "Sobre ámbitos arquitectónicos y vida reglar del clero. La canónica de la Seu Vella de Lleida”, Seu Vella. Anuari d'història i cultura, 3 (200I), pp. I5I-I90.

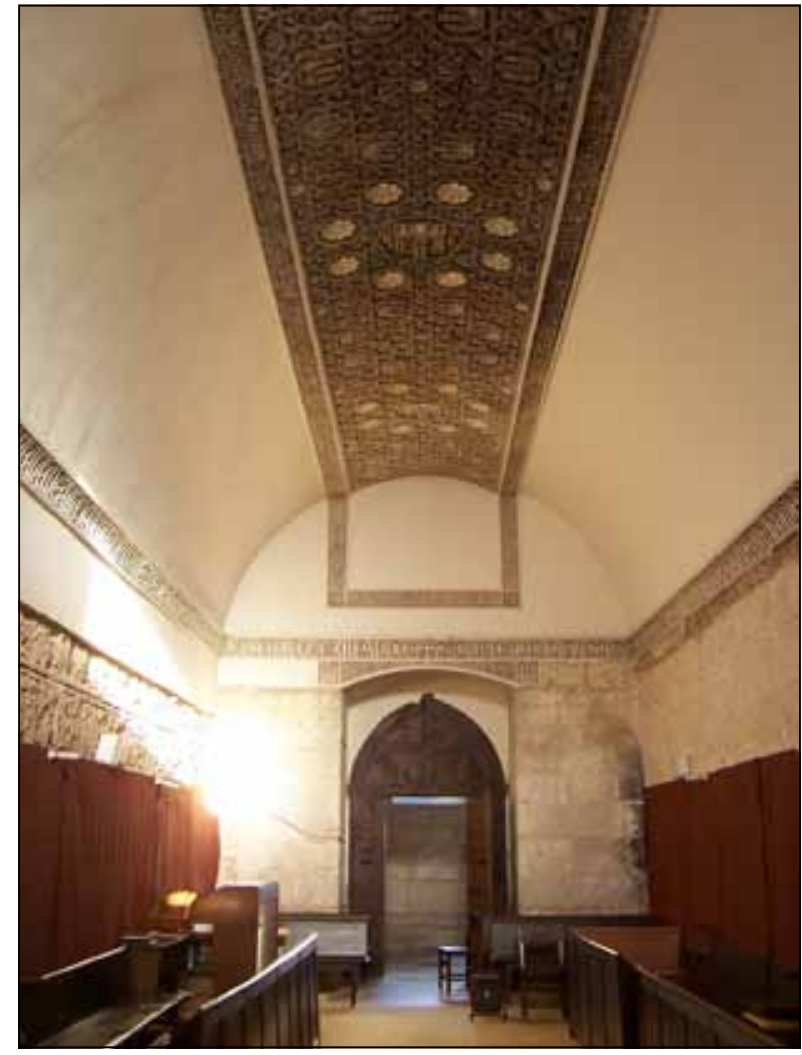

Fig. 6 - Santa María la Real de Las Huelgas. Locutorio, visto desde el Este.

Foto, Antonio García Flores.

en Las Huelgas son una muestra del modelo. Sin salir del entorno benedictino y cisterciense, la recientemente descubierta Virgen de yeso del claustro del monasterio de Ripoll (fig. 3), la del machón noroeste del Santo Domingo de Silos o la Verge del claustre de Vallbona de les Monges (fig. 4) ejemplifican lo que aquí tratamos.

\section{EPIGRAFÍA Y LITURGIA. EL PASO A LA ENFERMERÍA}

Por último, junto al estudio comparativo, el documental y la costumbre litúrgica, en el monasterio de Las Huelgas también contamos con un precioso testimonio epigráfico. Como vimos atrás, el núcleo principal del monasterio está comunicado con las Claustrillas, la capilla de la Asunción y, lógicamente, la enfermería, me- 
diante un paso situado en el extremo meridional, entre las dependencias de la panda Este del claustro de San Fernando. Éste fue cubierto mediante una bóveda de cañón apuntado en cuyo centro se situó una gran ataurique de yesos, representando los castillos del Reino entre decoración. Lo que aquí nos interesa es la faja de la que arranca la bóveda, cortada antes de la bifurcación del paso hacia las Claustrillas y a la capilla de Santiago y en la que se recoge la invocatio de la oración de la Salve y de la liturgia de Completas, de la que dicha oración solía funcionar como final ${ }^{29}$ (fig. 5). Como bien recogió Amancio Rodríguez López y recientemente ha analizado Álvaro Castresana, conservamos el siguiente fragmento partido:

[Crux] Visita, quaesumus, Domine, habitationem istam, et omnes insidias inimici ab ea longe repelle angeli tui [...] (Ad te) clamamus exules filii Eve ad suspiramus gementes et flentes in hac lacrimarum val de Eva ergo advocata nostra ${ }^{30}$

El hecho de que la inscripción se halle incompleta clarifica que las yeserías fueron mayores y que debieron desarrollarse por todo el espacio que nos ocupa, aunque en un momento que desconocemos de la historia constructiva del monasterio, éste se remodeló eliminando parte de la inscripción. Quizás se tratara de la misma época en la que pudo intervenirse sobre la puerta de comunicación entre nuestro paso y las Claustrillas, un gran arco apuntado con grueso bocel y sobre columnas con capiteles que, además de situarse a una cota altimétrica más baja que el actual suelo del paso, tiene la singularidad de no contar con talonamiento para albergar las hojas de sus posibles puertas, matiz que si bien no es

\footnotetext{
${ }^{29}$ CARRERO SANTAMARÍA, E., "Observaciones sobre la topografía sacra y cementerial de Santa María la Real de las Huelgas, en Burgos, y su materialización arquitectónica." La clausura femenina en España. Actas del Simposium (I), San Lorenzo de El Escorial, 2004, pp. 695-716.

${ }^{30}$ RODRÍGUEZ LÓPEZ, A., El Real Monasterio de Las Huelgas de Burgos y el Hospital del Rey, 2 vols., Burgos, 1907, II, p. 259. Sigo la lectura completa de CASTRESANA LÓPEZ. A., Corpus Inscriptionum Christianarum et Mediaevalium Provinciae Burgensis (ss. IV-XIII), tesis doctoral inédita, Universidad Autónoma de Madrid, 2014, pp. 149-.
}

definitorio sí que podría estar indicando que se trata de un elemento cambiado de lugar o remontado.

Junto a éstas yeserías, en la dependencia vecina paralela hacia el norte, encontramos otro conjunto de yesos vinculables al del paso anterior (fig. 6). Cerrada e interpretada como el locutorio del monasterio, en realidad se trata de otro paso con una gran puerta abierta hacia oriente, hoy convertida en ventana. Tocante a los yesos, aquí, el arranque de la bóveda de cañón está recorrido por una filacteria en la que aparecen fragmentos de salmos 24 y I4I, entre los que da inicio el Ad te levavi animam meam, cantado en el introito del primer domingo de Adviento. Un fragmento de nuevo incardinado con la figura de la Virgen:

[Cruz] Ad te levavi animam meam. Deus meus, in Te confido, non erubescam neque irrideant me inimici mei et enim universi qui Te expectant non confundentur vias tuas. Domine, demonstra michi et semitas tuas edoce me. Libera me, Domine, a persequentibus me quia confortati sunt super me. Educ de custodia animam meam ad confitendum nomini tuo. Me expectant iusti don retribuas michi Era Mill CCC XIII annos ${ }^{31}$

Hágase notar que, siguiendo las instrucciones del directorio franciscano de Arbiol, estos salmos eran rezo frecuente en la liturgia de la visita de los enfermos y, por lo tanto, perfectamente acordes con su función como epígrafes parlantes de un rito litúrgico de un uso ceremonial de la arquitectura ${ }^{32}$. Respecto la fecha de finalización de la obra, -como reza la cartela en la $E R A$ MILL CCC XIII ANNOS, es decir el año de I275-, ésta concede a las yeserías una cronología algo posterior a la del claustro de San Fernando, si seguimos las cronologías propuestas de Leopoldo Torres Balbás para todo el conjunto decorativo ${ }^{33}$.

\footnotetext{
${ }^{31}$ CASTRESANA, op. cit., pp. I47-I48.

32 ARBIOL, A., Visita de enfermos y exercicio santo de ayudar a bien morir con las instrucciones más importantes para tan sagrado ministerio, Madrid, I786, p. 163.

${ }^{33}$ TORRES BALBÁS, "Las yeserías", op. cit., pp. 2I3-2I4.
} 


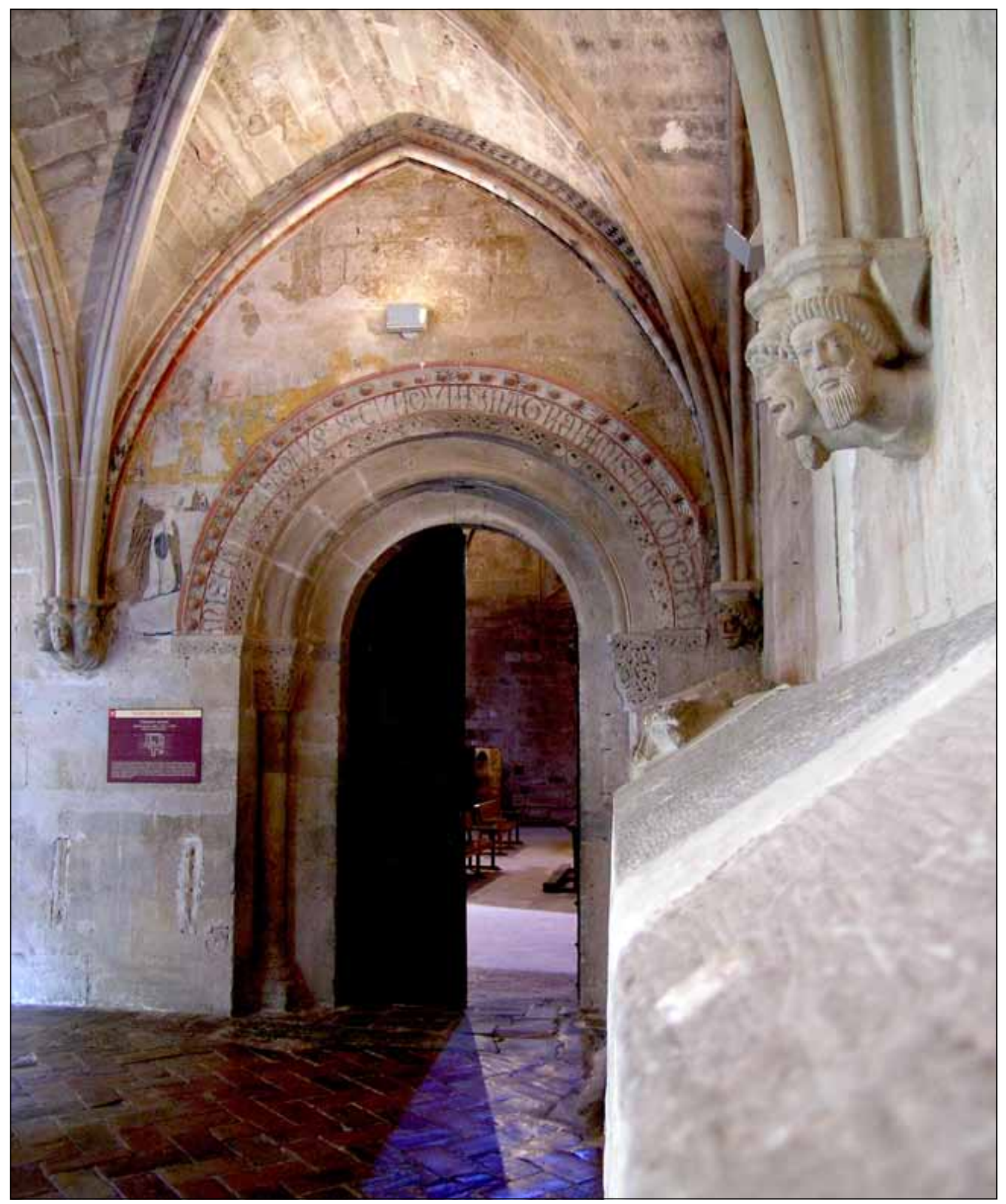

Fig. 7 - Santa María de Veruela (Zaragoza). Puerta de entrada a la iglesia desde el ángulo noreste del claustro. 
Los dos pasos de comunicación con la zona oriental del monasterio conllevan algunas complicaciones topográficas, habituales en buena parte de los monasterios, ante la falta ocasional de definición espacial de ambas dependencias, consideradas canónicas en la organización del claustro cisterciense $\mathrm{e}^{34}$. A pesar de tener su extremo oriental rehecho en fechas modernas, el paso sur debió estar siempre abierto hacia la zona de Claustrillas. También lo estuvo el norte y que, acordes con la tradición, efectivamente debió alojar el locutorio donde se repartía el trabajo diario entre la comunidad. No debe extrańarnos el hecho de hallar dos estancias abiertas hacia el exterior y que ambas sirvieran de paso, asunto que se constata en otros edificios del Císter europeo, sin ir más lejos, en las abadías vallisoletanas de Matallana y Valbuena ${ }^{35}$.

Si se había propuesto que ambas estancias -locutorio y paso- y su cubrición de yesos pudieron ser realizadas como escenario para el traslado de los restos de los fundadores desde la capilla de la Asunción hasta su emplazamiento definitivo en la iglesia ${ }^{36}$, sin dudar que ambos espacios participaran en dicha ceremonia, en mi opinión las razones para su ejecución se hallaron en la propia liturgia cotidiana de las monjas. Como hemos visto en las páginas previas, no hay lugar a dudas de que nos hallamos ante un escenario procesional pero éste trasciende un hecho puntual como el traslado de los cuerpos de Alfonso VIII y Leonor de Inglaterra hasta la nueva iglesia. El paso y el locutorio de Las Huelgas fueron un marco arquitectónico litúrgico subrayado mediante los epígrafes de sus muros, pero que debe ser puesto en clara relación con la liturgia mariana que conducía las procesiones claustrales y sus estaciones, además de tratarse del paso a la enfermería por el que discurrían determinadas procesiones, incluidas aquéllas en las que se trasladaba al difunto -no sólo a los reyes- de un lado a otro del conjunto, de la enfermería a la iglesia, hasta su

\footnotetext{
${ }^{34}$ ABAD CASTRO, C., "El pabellón de monjes", en Monjes y monasterios. El Císter en el medievo de Castilla y León, coord. I. G. Bango, Valladolid, 1998, pp. 187-203.

${ }^{35}$ GARCÍA FLORES, A., op. cit., p. 67.. Sobre el locutorio de Las Huelgas, ABAD CASTRO, C., "Locutorio. Santa María la Real de Las Huelgas (Burgos)", en Monjes y monasterios, op. cit., p. 226.

${ }^{36}$ PALOMO y RUIZ SOUZA, op. cit., pp. 35-37.
}

sepelio. No es un caso único en el que el epígrafe como huella litúrgica nos indica el uso de un ámbito, un paso, una puerta,... Por poner un simple ejemplo vinculado a monjes, claustros y procesiones, en el también cisterciense monasterio de Veruela, la puerta de comunicación entre la galería Este del claustro y la iglesia muestra unas deterioradas pinturas, datables entre los siglos XIV y $\mathrm{XV}$, en las que dos monjes se dirigen orando al Trono rodeado de ángeles. Acompañándolas, la inscripción MISERERE MEI DEUS SECUNDUM MAGNAM MISERICORDIAM TUAM se desarrolla alrededor de la rosca del arco (fig. 7). Se trata del primer verso del Salmo 5I, en clara alusión a la procesión de los salmos penitenciales -Sal 6, 32, 38, 5I, IO2, I30, y I43-que tenía lugar en el claustro, arrancando precisamente del ángulo de comunicación entre la panda capitular y la iglesia, acto que todavía era así recogido en el moderno Ritual de los usos de Císter: ... el viernes quédense en el primer ángulo del claustro esperando la procesión de los Psalmos penitenciales que el convento hace después. ${ }^{37}$

\section{CONCLUSIONES}

Llegados a este punto, insistamos en el gran claustro de San Fernando y su entorno como un escenario procesional básico en el desarrollo de la liturgia en Las Huelgas. Según se ha indicado, desde una perspectiva simbólica, efectivamente sus yeserías parecen hacer las veces de un gran palio procesional que, con sus telas orientales y los emblemas del reino, cubriera el discurrir litúrgico de las monjas bajo sus bóvedas de cañón apuntadas. Bien sabemos que sobre la superficie del claustro y dependiendo del año litúrgico, se realizaban una cantidad variable de paradas que iban desde la una a las cuatro. En el caso de la galería Este de Las Huelgas, además contamos con dos estancias que tuvieron este indudable uso estacional: el locutorio y el paso a la enfermería. En ambos casos, una filacteria escrita recubre sus muros a la altura del arranque de las bóvedas. Que los textos recogidos en ambos conjuntos

\footnotetext{
${ }^{37}$ CARRERO, “Arte y liturgia en los monasterios”, op. cit.
} 
sean, precisamente, fuentes litúrgicas emparentadas con las procesiones que comunicaban la iglesia principal con la capilla de la enfermería no hace más que subrayar esta cuestión. Destaquemos además que, en el Códice de polifonía de Las Huelgas, precisamente hallamos de las antífonas marianas más importantes, una Salve Regina gloriae, acompañada de la Salve Virgo regia y la Salve, Virgo virginum, que muy bien pudieron ser interpretadas por las monjas durante las procesiones en el monasterio al pasar, necesariamente, por los pasos de circulación entre el claustro de San Fernando y hacia las Claustrillas, zona de la enfermería ${ }^{38}$.

Una estancia más pudo tener su papel en el asunto. Me refiero a la capilla de Santiago, una singular pieza que completa la topografía sagrada de la zona sureste del conjunto monástico. Vecina al noreste de la capilla de la Asunción, presenta el claro esquema de edificio de nave única rematado al Este en un presbiterio cuadrangular cubierto, en este caso, por una armadura. Presenta una relación directa con el entorno del claustro de San Fernando, al comunicarse con éste mediante un paso abierto y el pasaje del pabellón de monjas, del que tratamos. Las yeserías del arrocabe de su tramo recto y del arco triunfal han datado sus obras en el último cuarto del siglo XIII, quizás en paralelo con el reinado de Alfonso $\mathrm{X}^{39}$. Su interpretación pasa por tratarse de una fundación cementerial, en la que quizás se perpetuó una tradición que Amancio Rodríguez López recogía a finales del siglo XIX, según la cual allí se hallaba uno de los cementerios del conjunto y que no fue el lugar de la coronación o la toma de armas de los reyes de Castilla, según se había propuesto en alguna que otra ocasión ${ }^{40}$.

Tradicionalmente las Claustrillas y su entorno habían pasado por tratarse de restos de un palacio real o las huellas del primer monasterio cisterciense. Hoy podemos ofrecer una lectura diferente siguiendo las constantes

\footnotetext{
${ }^{38}$ Utilizo la edición de ASENSIO PALACIOS, El Códice de Las Huelgas, op. cit.,, pp. 96, IIO, II8-II9

${ }^{39}$ AZCÁRATE RISTORI, J. M. de, "La capilla de Santiago en Las Huelgas de Burgos", Reales Sitios, 28 (197I), pp. 49-52.

${ }^{40}$ RODRÍGUEZ LÓPEZ, op. cit., II, p. 273. Sobre el tema de la Coronación y sus implicaciones arquitectónicas, CARRERO, "Observaciones sobre la topografía” op. cit., y "The use and creation of space”, op. cit.
}

funcionales de la arquitectura del Císter en consonancia con la tradición benedictina, aún en un monasterio tan singular como Las Huelgas de Burgos y en una época en la que la polifuncionalidad arquitectónica fue constante. De este modo, las Claustrillas no fueron otra cosa que el patio de la enfermería y del palacio abacial; la capilla de la Asunción el oratorio inicial que -tras la consagración de la gran iglesia del monasterio en I279- pasaría a hacer definitivamente las funciones de capilla de la enfermería y del palacio abacial y, por último, la capilla de Santiago fue una capilla cementerial en una de las zonas de enterramiento del conjunto. Además, la funcionalidad litúrgica del entorno en las procesiones monásticas queda rotundamente refrendada mediante un testimonio epigráfico. El paso que comunica esta zona con el claustro mayor del monasterio fue circundado por una faja de yeserías en las que se escribieron fragmentos de la Salve y de la liturgia de Completas, a la par que en la vecina sala que se identifica con el locutorio se colocaron epígrafes con salmos de especial significación litúrgica. Para ámbitos tan prosaicos como una salida a la huerta y un locutorio parece una decoración demasiado lujosa y con claras implicaciones cultuales en relación a su función, ampliable ahora a la de estaciones en los recorridos procesionales de la comunidad. No hay lugar a dudas de que en el locutorio, el paso a la huerta y en las capillas de la Asunción y de Santiago, la importancia de la liturgia procesional monástica debió ser básica, hundiendo sus raíces en una tradición bien refrendada por costumbreros benedictinos y cistercienses desde pleno siglo XI en adelante. La tan traída y llevada presencia de los reyes en el monasterio con palacios, sepulcros y ámbitos de coronación debe ser reorientada desde sus orígenes historiográficos románticos hacia una contemporánea interpretación vinculada a la vida cotidiana y sobre todo litúrgica de una comunidad monástica femenina muy singular, como la de Santa María la Real de Las Huelgas. 